\title{
Dor torácica e dispneia de esforço
}

\author{
Chest pain and dyspnea on exertion
}

Os autores relatam 0 caso de uma mulher de 59 anos, com antecedentes de síndrome depressivo, dislipidémia, hérnia do hiato e Doença de Parkinson. A doente apresentava queixas de dor pré-cordial de intensidade em crescendo, desencadeada pelo esforço e com alívio após repouso, sem irradiação, sem sinais ou sintomas acompanhantes e sem outros fatores desencadeantes. Referia ainda dispneia para médios esforços e omalgia esquerda de longa data. Sem outras queixas, nomeadamente do foro cardíaco ou gastrintestinal. Pelas características da dor realizou estudo dirigido para doença coronária, incluindo cintigrafia de perfusão do miocárdio, que não apresentou alterações. Efectuou ainda radiografia torácica que evidenciou volumosa hérnia do hiato com deslizamento intratorácico, confirmada em trânsito esofago-gastro-duodenal e posteriormente por TC torácica que mostrou a presença de volumosa hérnia do hiato esofágico, com um componente de deslizamento ( junção esofago-gástrica em topografia torácica) e com um grande componente para-esofágico, contendo praticamente na totalidade o corpo e a porção proximal do antro gástrico com rotação gástrica (volvo) sob o eixo mesentero-axial (Figura 1 y 2). A doente foi submetida a cirurgia de Nissen por via laparoscópica que decorreu sem intercorrências. Desde a cirurgia refere desaparecimento da dor torácica, da omalgia esquerda e da dispneia para médios esforços.

A hérnia do hiato ocorre quando há prolapso de uma estrutura abdominal para a cavidade torácica pelo hiato esofágico ${ }^{1}$. As hérnias do hiato dividem-se em por deslizamento, quando a junção esofagogástrica se encontra acima do diafragma, e paraesofágicas, quando há protusão do fundo gástrico para a cavidade torácica, acompanhado ou não pela junção esofago-gástrica, mantendo a relação anatómica entre estas duas estruturas ${ }^{1}$. Todas as hérnias do hiato paraesofágicas sintomáticas ou na presença de volvo devem ser corrigidas cirurgicamente ${ }^{1}$. A abordagem cirurgica mais comum atualmente é a cirurgia de Nissen por via laparoscópica, uma vez que implica menor morbilidade e tempos de internamento mais curtos que por laparotomia². A cirurgia de Nissen consiste em envolver a junção esofago-gástrica a $360^{\circ} \mathrm{com}$ o fundo do estômago (Figura 3). A longo prazo, a taxa de recorrência é baixa e os doentes mantém-se assintomáticos ${ }^{3}$.

Figura 1. Corte sagital de TC em janela de mediastino mostrando a maioria do estomago em posição intra-torácica

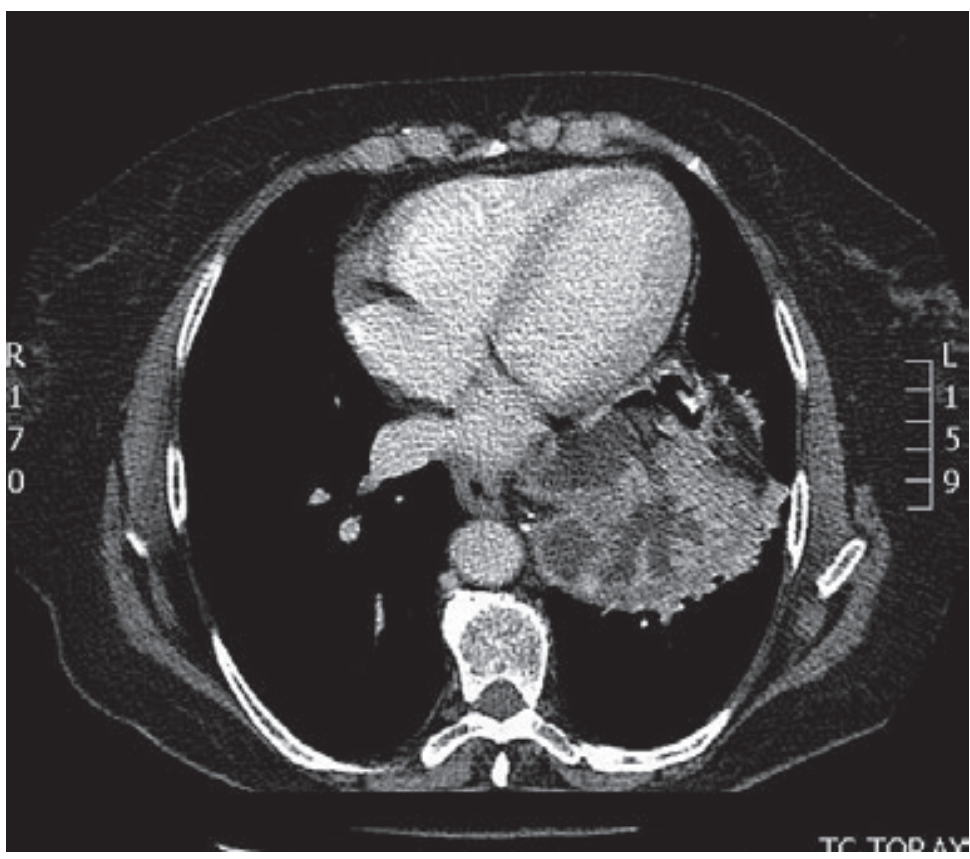

Figura 2. Corte sagital de TC toraco-abdominal em janela de mediastino mostrando a maioria do estómago em posição intratorácica

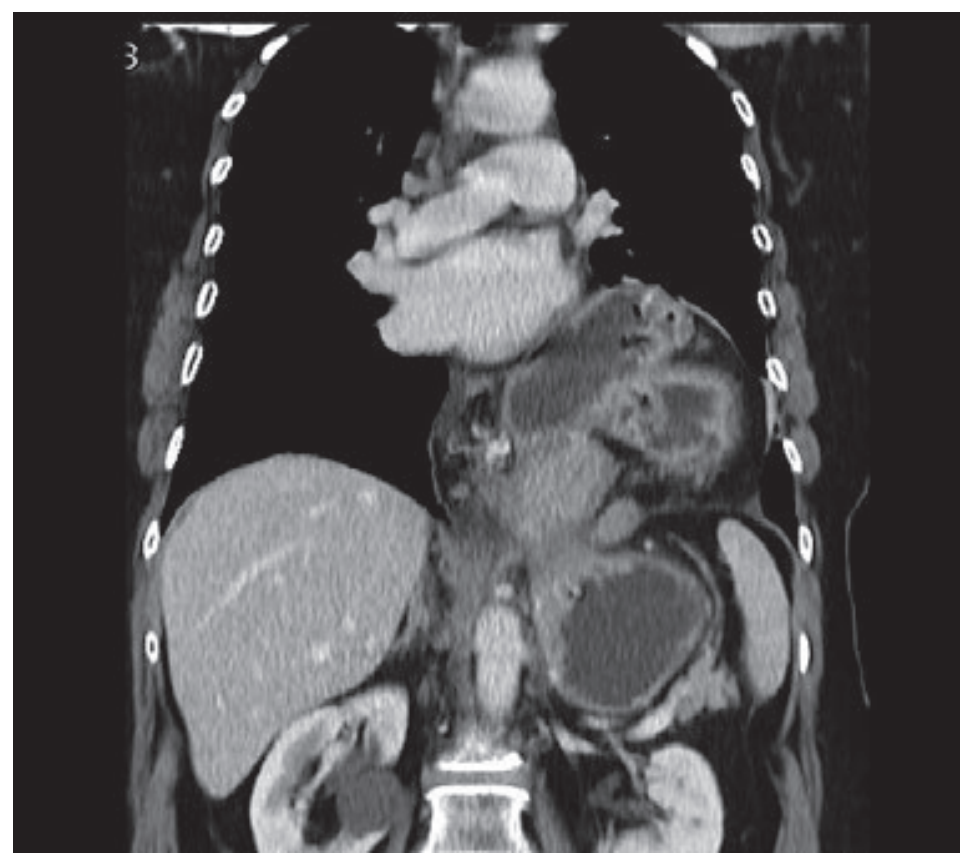




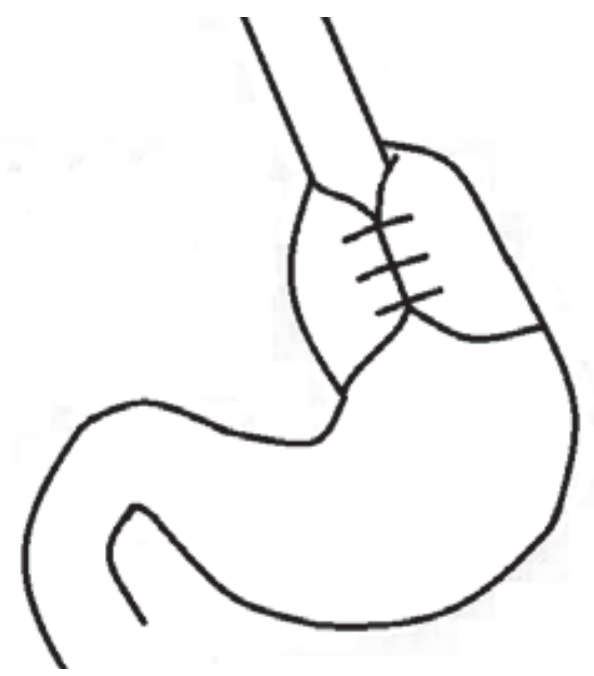

Este caso apresenta duas particularidades: por um lado a exuberância da hérnia do hiato com a quase totalidade do estomago em localização intra-torácica e, por outro lado, a clínica sugestiva de angor como manifestação principal da doença.

\section{Bibliografia}

1. Kohn GP, Price RR, Demeester SR, Zehetner J et al. Guidelines for the management of hiatal hernia. Surg Endosc. 2013 Dec;27(12):4409-28. doi: 10.1007/s00464013-3173-3. Epub 2013 Sep 10

2. Salminen P. The laparoscopic Nissen fundoplication-a better operation?. Surgeon. Aug 2009;4:224-227

3. Andujar JJ, Papasavas PK, Birdas T, Robke $\mathrm{J}$ et al. Laparoscopic repair of large paraesophageal hernia is associated with a low incidence of recurrence and reoperation. Surg Endosc. 2004 Mar;18(3):444-7. Epub 2004 Feb 2.

\section{Diagnóstico: Volumosa hérnia do hiato}

\section{Magda Sousa, Nuno Gatta}

Serviço de Medicina Interna, Centro Hospitalar do Baixo Vouga - Aveiro

\section{Correspondencia: nuno.gatta@hotmail.com}

Como citar este artículo: Sousa M, Gatta N

Dor torácica e dispneia de esforço. Galicia Clin 2015; 76 (1): 41-42

Recibido: 09/11/2014; Aceptado: 19/01/2015 